
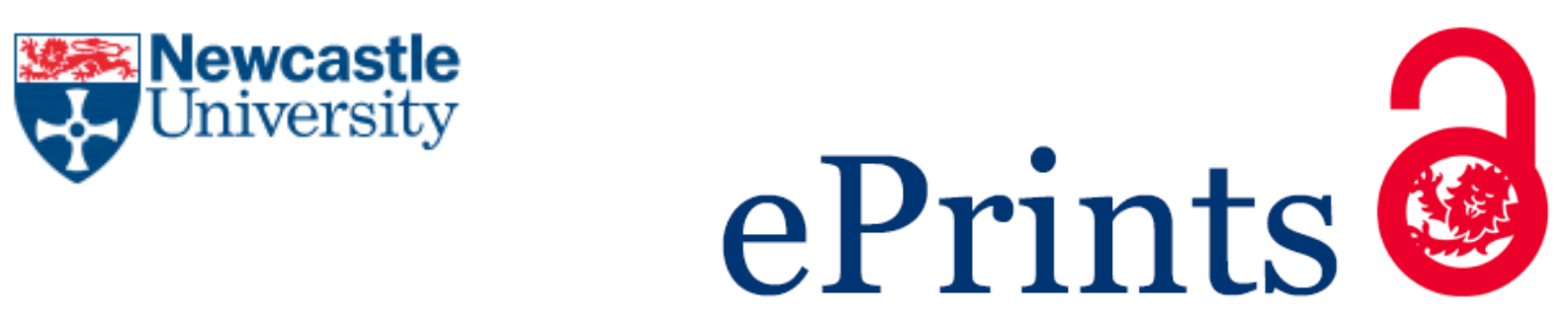

\author{
Binek A, Petrus ML, Huber N, Bristow H, Hu Y, Bein T, Docampo P. \\ Recycling Perovskite Solar Cells To Avoid Lead Waste. \\ ACS Applied Materials \& Interfaces 2016, 8(20), 12881-12886.
}

\title{
Copyright:
}

This document is the Accepted Manuscript version of a Published Work that appeared in final form in ACS Applied Materials \& Interfaces, copyright (c) American Chemical Society after peer review and technical editing by the publisher. To access the final edited and published work see http://dx.doi.org/10.1021/acsami.6b03767

Date deposited:

$31 / 05 / 2017$

Embargo release date:

05 May 2017 


\section{Recycling perovskite solar cells to avoid lead waste}

Andreas Binek, ${ }^{1, \dagger}$ Michiel L. Petrus, ${ }^{1,+}$ Niklas Huber, ${ }^{1}$ Helen Bristow, ${ }^{1,2}$ Yinghong Hu, ${ }^{1}$ Thomas Bein $^{1 *}$ and Pablo Docampo ${ }^{1 *}$

${ }^{\dagger}$ These authors contributed equally to the work.

${ }^{1}$ Department of Chemistry and Center for NanoScience (CeNS), University of Munich (LMU) Butenandtstr. 5 - 13 (Haus E) 81377 Munich, Germany

${ }^{2}$ University of York, Heslington, York, YO10 5DD, United Kingdom

\section{Corresponding Author}

E-Mail:*bein@1mu.de and *pablo.docampo@cup.lmu.de

\section{Keywords}

Methylammonium lead iodide, $\mathrm{MAPbI}_{3}$, recycling, hybrid perovskite, environment 


\begin{abstract}
Methylammonium lead iodide $\left(\mathrm{MAPbI}_{3}\right)$ perovskite based solar cells have recently emerged as a serious competitor for large scale and low-cost photovoltaic technologies. However, since these solar cells contain toxic lead, a sustainable procedure for handling the cells after their operational lifetime is required to prevent exposure of the environment to lead and to comply with international electronic waste disposal regulations. Herein, we report a procedure to remove every layer of the solar cells separately, giving the possibility to selectively isolate the different materials. Besides isolating the toxic lead iodide, we show that the $\mathrm{PbI}_{2}$ can be reused for the preparation of new solar cells with comparable performance and in this way avoid lead waste. Furthermore, we show that the most expensive part of the solar cell, the conductive glass (FTO), can be reused several times without any reduction in the performance of the devices. With our simple recycling procedure, we address both the risk of contamination and the waste disposal of perovskite based solar cells, while further reducing the cost of the system. This brings perovskite solar cells one step closer to their introduction into commercial systems.
\end{abstract}

TOC GRAPHIC

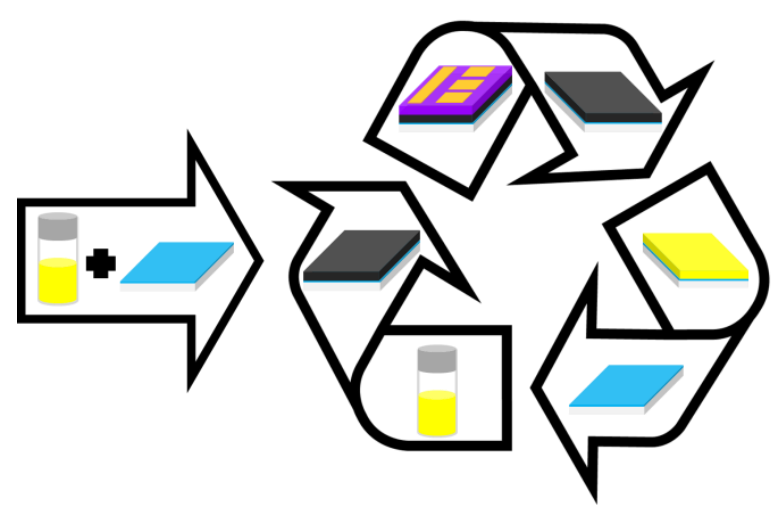

Illustration of the recycling circle for $\mathrm{MAPbI}_{3}$-based solar cells 


\section{Introduction}

Solar energy is the most abundant renewable energy source; its harvesting on a global scale shows the potential to fulfill the world's energy demand at low cost while minimizing greenhouse gas emissions, in accordance with the United Nations' Paris Agreement. ${ }^{1}$ Presently, hybrid halide perovskite materials such as methylammonium lead iodide $\left(\mathrm{MAPbI}_{3}\right)$ have emerged as extremely efficient light harvesters in solid-state solar cells. ${ }^{2-3}$ Through optimization of the fabrication process, ${ }^{4-6}$ the annealing process $^{7-8}$ and the interfaces, ${ }^{9-10}$ perovskite solar cells have already exceeded $20 \%$ power conversion efficiency (PCE), comparable to established commercial technologies such as CIGS, CdTe or poly-Si, and further improvements are expected. ${ }^{11}$

Despite their high PCEs, perovskite solar cells still have not entered commercial markets at this time. One of the current major issues is the heavy metal lead used in the perovskite structure in high efficiency devices, which is known to be a significant hazard to the environment and human health. ${ }^{12-13}$ The toxic effects of lead are ascribed to its harmful interactions with proteins, which cause changes in the folding of the proteins resulting in reduced activity and loss of function.

Because of this, lead is harmful to all living organisms. ${ }^{14-16}$ While researchers worldwide have made progress towards developing perovskite photovoltaics based on lead alternatives, ${ }^{17}$ these devices show poorer photovoltaic performance and lower stability, making them less likely to be used on a large scale. It is thus important to prevent release of lead into the environment through device encapsulation.

Nevertheless, at the end of their working lifetime, the devices will have to be collected according to international electronic waste disposal regulations. ${ }^{18-19}$ This still leaves the challenges of isolating the toxic elements from the panels and handling of the waste streams. Developing a 
recycling strategy in which all the different layers of the panels can be separately collected and reused could resolve the waste issues, and possibly is economically attractive.

Here we study the feasibility of recycling different layers of perovskite solar cells with respect to their environmental and cost impact. In our approach, the layers of a planar perovskite-based solar cell can be removed and recovered one by one, greatly simplifying the recycling process. In addition, we demonstrate that the expensive conductive glass as well as the toxic lead precursor can be reused. We believe that this approach could bring perovskite solar cells one step closer to their introduction into commercial systems. 


\section{Results}

In order to recycle perovskite solar cells, we have developed a procedure to strip down the device layer by layer. We performed this protocol on methylammonium lead iodide $\left(\mathrm{MAPbI}_{3}\right)$ perovskite solar cells with a planar device architecture, which were prepared following the synthetic route described by Xiao et. $a l .^{5}$ In the first step, the gold contact is removed using adhesive tape (step I, Figure 1). Secondly, the Spiro-OMeTAD based hole-transporting layer is selectively removed via immersion of the device substrate into chlorobenzene (step II, Figure 1). Brief immersion in doubly distilled water then reconverts the perovskite layer into $\mathrm{PbI}_{2}$ and methylammonium iodide (MAI), and the MAI is directly extracted into the water (step III, Figure 1). In step IV (Figure 1), $\mathrm{PbI}_{2}$ is removed from the substrate by immersing the sample for a short time in dimethylformamide (DMF). Extended washing of the device in DMF will also result in the removal of the $\mathrm{TiO}_{2}$ layer (see Supporting Information), resulting in a clean FTO substrate (step V, Figure 1). 

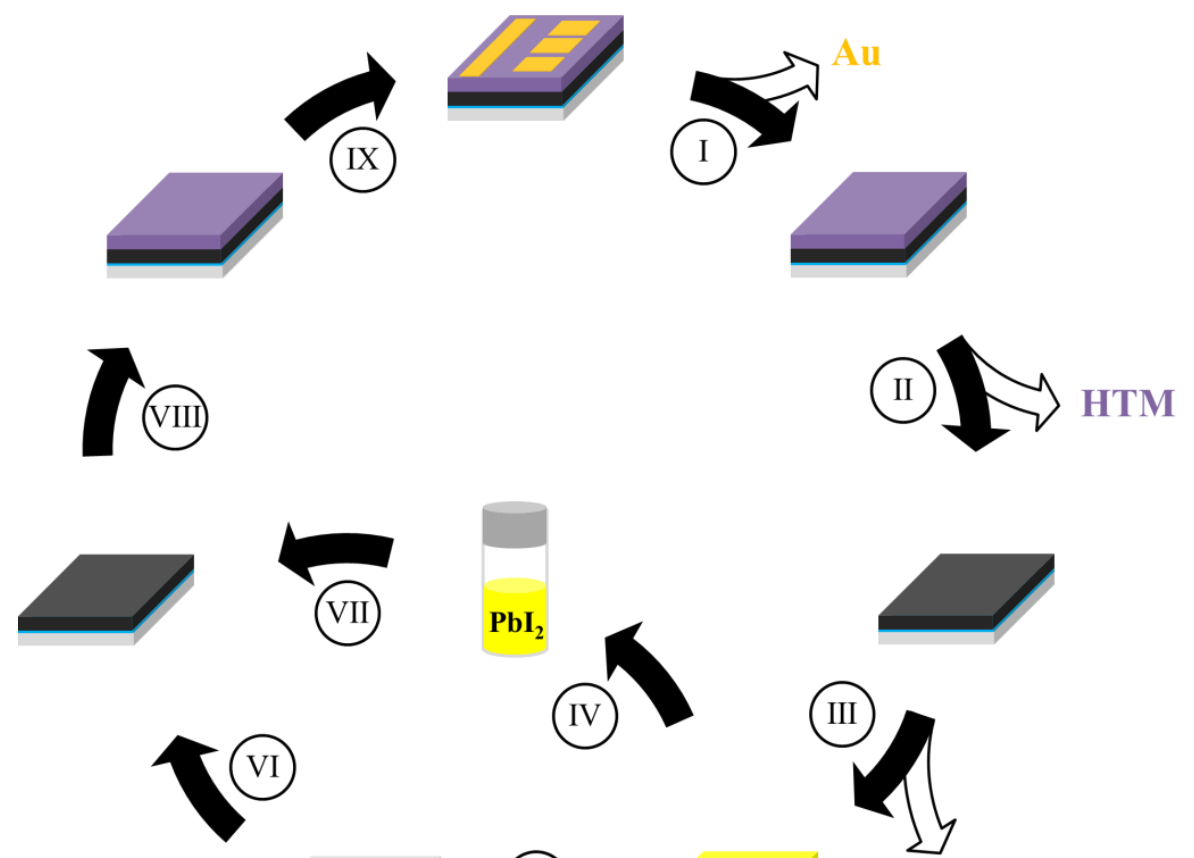

FTO
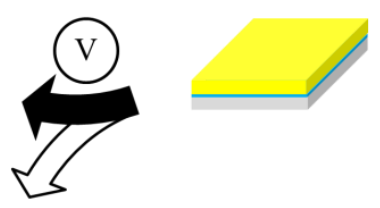

(III)

$\mathrm{TiO}_{2}$

Figure 1. Recycling procedure for perovskite solar cells. I: Removing Au electrode with adhesive tape. II: Removing the HTM by immersing in chlorobenzene. III: Transformation of the perovskite into MAI and $\mathrm{PbI}_{2}$ and extraction of MAI in water. IV \& V: Removal of $\mathrm{PbI}_{2}$ and $\mathrm{TiO}_{2}$ using DMF. VI: Preparing a new $\mathrm{TiO}_{2}$ film. VII: Formation of the perovskite film on recycled FTO from recycled $\mathrm{PbI}_{2}$. VIII: Preparation of the HTM layer. IX: evaporation of the Au top electrode.

The isolation of toxic lead iodide is important because of its harmful effects to the environment. ${ }^{11}$ However, by reusing the collected $\mathrm{PbI}_{2}$, the environmental impact would be even further reduced, leaving no toxic waste. In addition, the described process opens the possibility to recycle the FTO substrate, MAI, Spiro-OMeTAD and gold layers. 


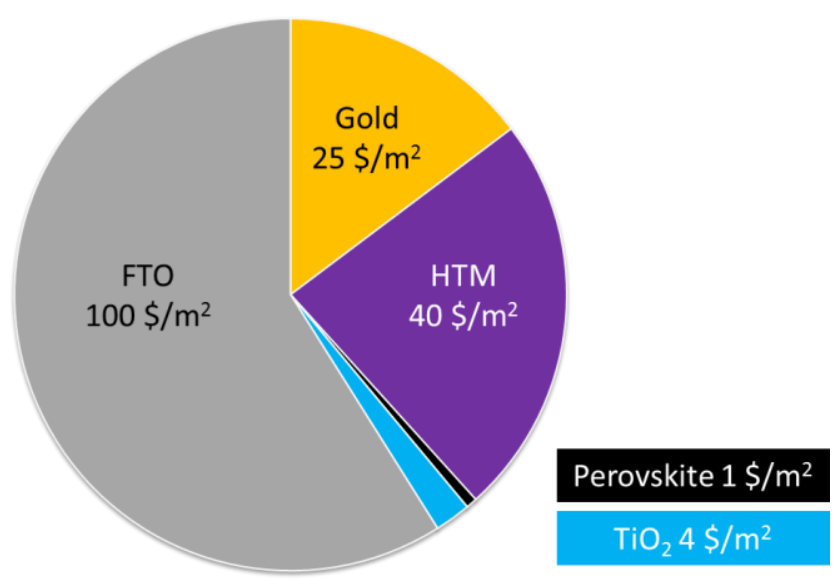

Figure 2. Pie chart displaying the estimated cost of the different layers in perovskite solar cells.

Cost analysis for different solar technologies such as organic (OPV), cadmium telluride (CdTe) and dye sensitized (DSSC) photovoltaics shows that the FTO/glass is a major factor of between $20-60 \%$ of the module cost. ${ }^{20-21}$ In our cost estimation (depicted in Figure 2) we have determined that this is also the case for perovskite solar cells. Alternatives for the commonly used FTO substrates have been reported in the literature, including ITO/glass, PEDOT:PSS ${ }^{22}$ or graphene. $^{23}$ However, to date, the best performance is still achieved with FTO substrates. Additionally, these alternatives are either more expensive, not commercially available or have not been scaled up yet. The hole transporting material is also a significant cost factor; however, recent publications have shown that several materials that can be produced at a fraction of the cost show the potential to compete with the current state-of-the-art Spiro-OMeTAD, ${ }^{24-26}$ making recycling of this material less critical. The gold top electrode will most likely also be replaced by other materials when perovskite solar cells are scaled up, for example by silver paste. ${ }^{27-28}$ The cost contribution of the perovskite layer consisting of $\mathrm{PbI}_{2}$ and $\mathrm{MAI}$ and the titanium dioxide layer is relatively small, and the recycling of these layers is less interesting from an economic point of view. Based on the above considerations, here we focus on the recycling of $\mathrm{PbI}_{2}$ for environmental reasons and on the FTO/glass for economical reasons. 


\section{Recycling of PbI2}

In the recycling process, $\mathrm{PbI}_{2}$ was removed from the substrate through DMF extraction (Step IV,

Figure 1). Recycling $70 \mathrm{dm}^{2}$ of perovskite film yields around $600 \mathrm{mg}$ of $\mathrm{PbI}_{2}$, which is enough to prepare $1 \mathrm{~mL}$ of a $1.25 \mathrm{M} \mathrm{PbI}_{2}$ solution. This permits the production of recycled $\mathrm{MAPbI}_{3}$ films with an area of around $2 \mathrm{dm}^{2}$. The large amount of perovskite film required to prepare the recycled $\mathrm{PbI}_{2}$ solution is the result of the significant material loss when preparing films using spin-coating techniques. On an industrial scale, spin-coating will most likely be replaced by other techniques, such as slot die coating, where material loss can be close to negligible thus making the recycling more efficient.
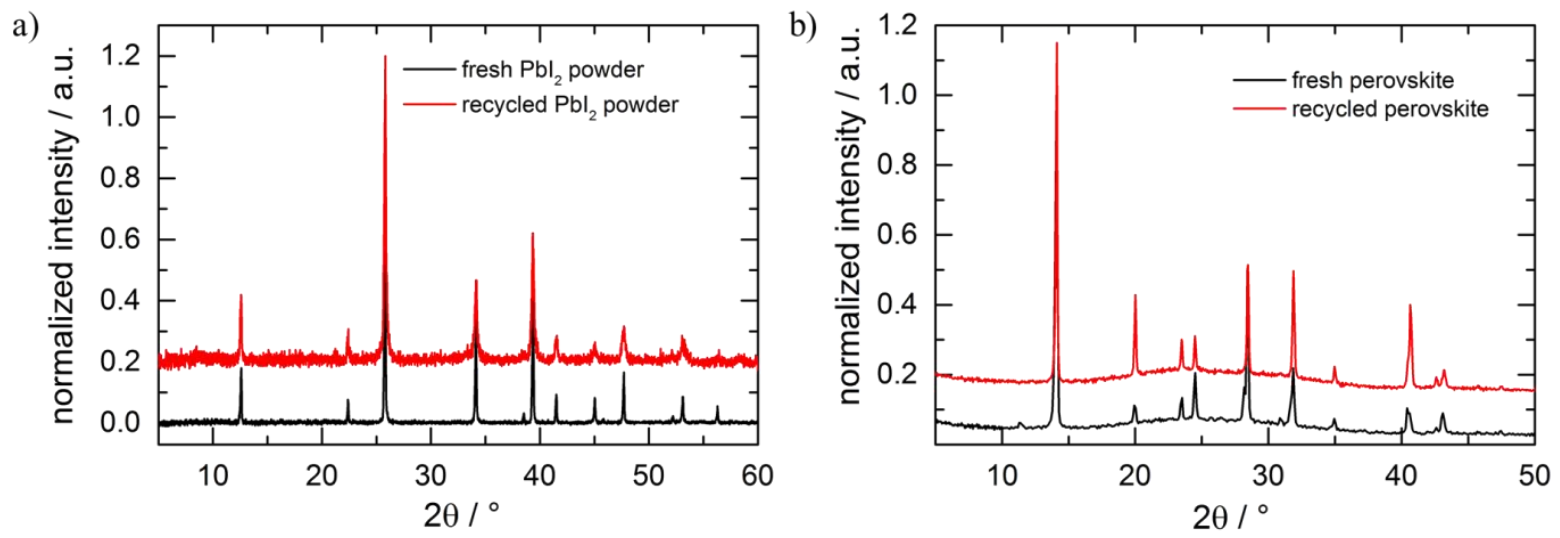

Figure 3. Comparison of the XRD patterns of recycled $\mathrm{PbI}_{2}$ and fresh $\mathrm{PbI}_{2}$ (a), and $\mathrm{MAPbI}_{3}$ perovskite films prepared from fresh $\mathrm{PbI}_{2}$ and from recycled $\mathrm{PbI}_{2}$ (b). The normalized XRD patterns are offset for clarity.

The recycled $\mathrm{PbI}_{2}$ was studied by ${ }^{1} \mathrm{H}-\mathrm{NMR}$ (in DMSO-d6) and no traces of Spiro-OMeTAD or other organic compounds were observed in its spectrum (Figure S1). The recycled $\mathrm{PbI}_{2}$ and perovskite films prepared from the recycled $\mathrm{PbI}_{2}$ were characterized by $\mathrm{XRD}$ and compared to the films prepared from fresh starting materials (Figure 3 a,b). No changes in the XRD patterns were 
observed for the recycled $\mathrm{PbI}_{2}$ and the resulting perovskite film. The observed reflections also correspond to the theoretical reflections of $\mathrm{PbI}_{2}$ and $\mathrm{MAPbI}_{3}$.

Photovoltaic devices prepared using the recycled $\mathrm{PbI}_{2}$ were characterized and their $J-V$ characteristics are shown in Figure 4. Although the devices show good performance with best efficiencies exceeding $12 \%$, their PCE is lower than that of devices prepared from highly pure $\mathrm{PbI}_{2}$ purchased from Sigma-Aldrich $(99 \%+)$, termed "fresh" in the rest of the article. The lower PCE mainly originates from a lower open circuit voltage ( $\left.V_{\mathrm{oc}} 0.95 \mathrm{vs} 1.03 \mathrm{~V}\right)$ and fill factor $(\mathrm{FF}, 65 \mathrm{vs}$ 74\%). This most likely originates from a small amount of impurities in the $\mathrm{PbI}_{2}$ solution, which were undetectable with NMR or XRD measurements. To examine this hypothesis, we recrystallized the recycled $\mathrm{PbI}_{2}$ from water in order to remove possible impurities in the material. ${ }^{29}$ Solar cells prepared from this recycled and recrystallized $\mathrm{PbI}_{2}$ (from here on termed "recrystallized") show improved device performance with PCEs up to $13.5 \%$ and an average of $12.5 \%$ (compared to an average of $13.0 \%$ for the fresh $\mathrm{PbI}_{2}$, Table 1) and a significant improvement in the $V_{\mathrm{oc}}$ and FF (see inset Figure 4). Scanning electron microscopy (SEM) cross-sectional images of the devices prepared from fresh and recycled $\mathrm{PbI}_{2}$ show similar morphology (Figure 4b, c), which is in line with the comparable device performance. This demonstrates (i) that our recycling process is able to isolate the toxic $\mathrm{PbI}_{2}$ from the perovskite solar cells, and (ii) that the recycled $\mathrm{PbI}_{2}$ can be reused for the preparation of efficient new solar cells. 
b)

a)

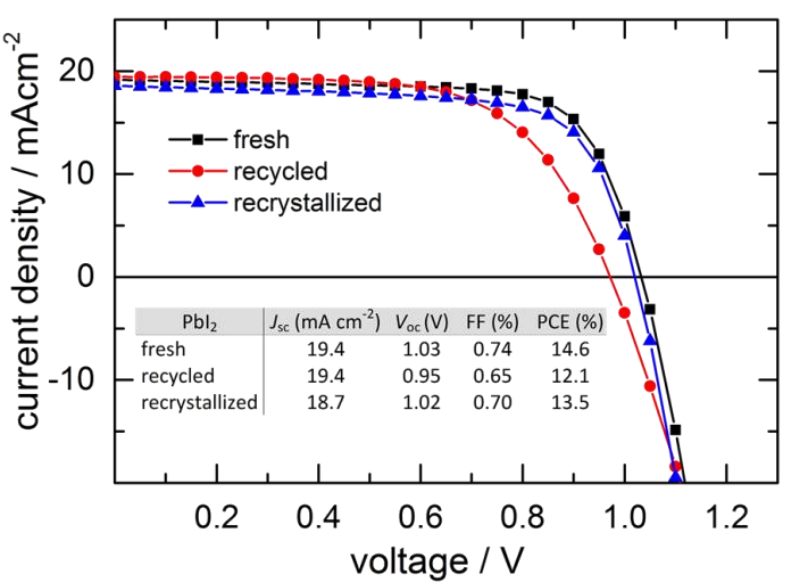

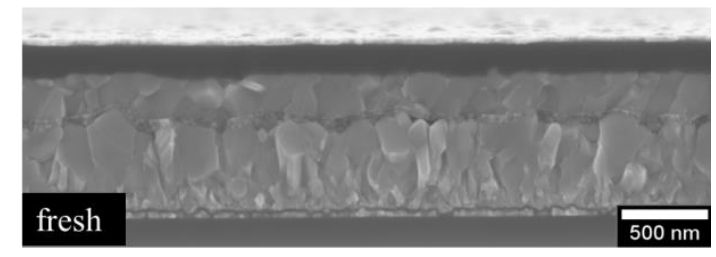

c)

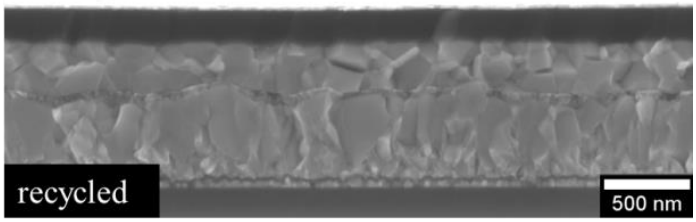

Figure 4. a) $J-V$ characteristics of perovskite solar cells prepared from fresh, recycled and recycled and recrystallized $\mathrm{PbI}_{2}$. SEM cross-section of solar cells prepared from $\mathrm{b}$ ) fresh $\mathrm{PbI}_{2}$ and c) recycled $\mathrm{PbI}_{2}$.

\section{Recycling the glass/FTO}

The cost analysis discussed above shows that the FTO/glass substrate is the most expensive part of the perovskite solar cells (for details see SI), and thus the most economically interesting layer to recycle. In a first approach, the $\mathrm{TiO}_{2}$-coated $\mathrm{FTO} /$ glass substrate was recycled directly after removing the $\mathrm{PbI}_{2}$ with $\mathrm{DMF}$. Photovoltaic devices prepared on these substrates showed a significant decrease in device performance over several recycling cycles (Figure S2). XRD studies showed that removing the $\mathrm{PbI}_{2}$ with $\mathrm{DMF}$ also degrades the underlying $\mathrm{TiO}_{2}$ layer, suggesting that this is the reason behind the lower device performance (for details see SI and Figure S2). However, the XRD study also revealed that complete removal of the $\mathrm{TiO}_{2}$ underlayer is possible by prolonged immersion in DMF. Since $\mathrm{TiO}_{2}$ is insoluble in $\mathrm{DMF}^{30}$ we expect that the solvent penetrates through pores in the $\mathrm{TiO}_{2}$, resulting in the delamination of the layer (see Figure S3).

To address this issue, a fresh electron-selective $\mathrm{TiO}_{2}$ layer was prepared on the recycled and cleaned FTO/glass substrate using the same deposition protocol. These devices show no loss in 
performance even after several recovery cycles (Figure 5 and Table 1). The devices show a relatively narrow distribution of PCEs (standard deviations just above 1\%) over a large set of 24 individual devices and no significant drop in any of the device performance parameters (Figure S4 and Table S1). The best cells show similar power conversion efficiencies between 14.6 and $15.4 \%$ for all batches, where the highest PCE was obtained on a three-times recycled substrate. The slightly higher PCEs on the recycled substrates may be the result of an improved coverage of $\mathrm{TiO}_{2}$ over the FTO substrate. Here, complete removal of the $\mathrm{TiO}_{2}$ layer by $\mathrm{DMF}$ immersion is unlikely and every cycle adds a fresh layer.

a)

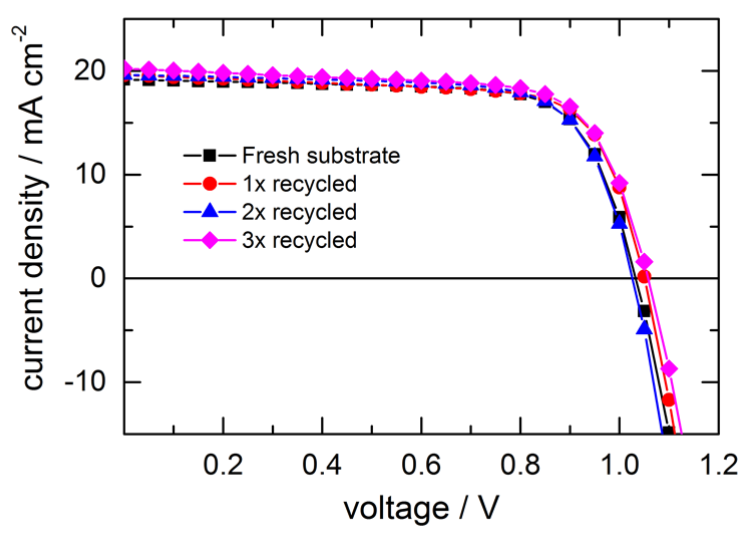

b)

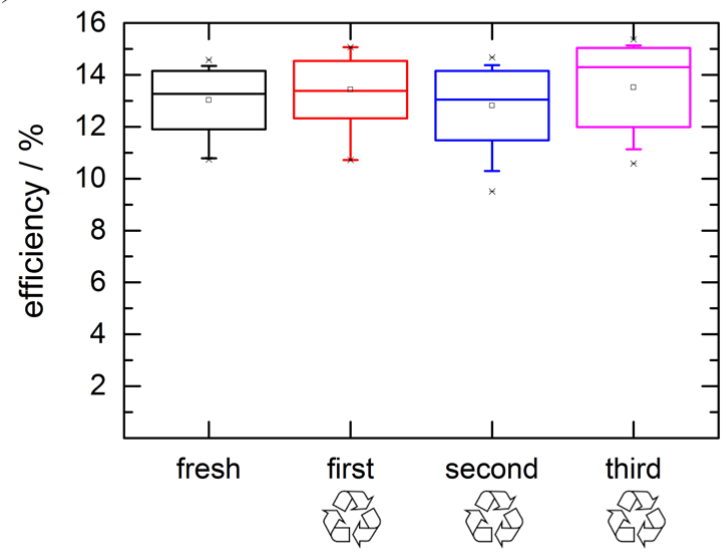

c)

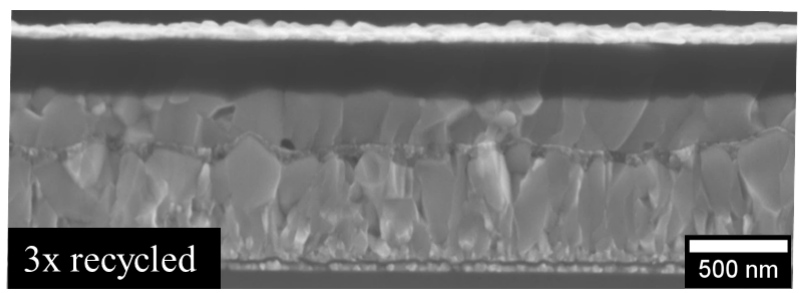

Figure 5. Device performance of solar cells prepared on recycled FTO/glass substrates. a) $J-V$ characteristics, b) bar diagram showing the average (circle), median (middle line), maximum, minimum (crosses) and 75 (box) and 95\% (small error bar) distribution of 24 individual cells for each of the recycling steps. c) SEM cross-section of a record cell prepared on a three-times recycled substrate. 
Table 1. Device performance after recycling the FTO substrate.

\begin{tabular}{ll|llll} 
& & $J_{\mathrm{sc}}\left(\mathrm{mA} \mathrm{cm}^{-2}\right)$ & $V_{\mathrm{oc}}(\mathrm{V})$ & FF $(\%)$ & PCE (\%) \\
\hline Fresh & Record & 19.2 & 1.03 & 73 & 14.6 \\
& Average & $18.2 \pm 1.2$ & $1.03 \pm 0.01$ & $69 \pm 4$ & $13.0 \pm 1.1$ \\
\hline First & Record & 19.6 & 1.05 & 72 & 15.1 \\
recycled & Average & $17.9 \pm 1.4$ & $1.04 \pm 0.01$ & $71 \pm 2$ & $13.4 \pm 1.1$ \\
\hline Second & Record & 19.6 & 1.03 & 72 & 14.7 \\
recycled & Average & $17.4 \pm 1.8$ & $1.04 \pm 0.01$ & $70 \pm 3$ & $12.8 \pm 1.3$ \\
\hline Third & Record & 20.2 & 1.06 & 71 & 15.4 \\
recycled & Average & $18.5 \pm 2.0$ & $1.04 \pm 0.01$ & $70 \pm 3$ & $13.5 \pm 1.5$ \\
\hline
\end{tabular}

\section{Discussion}

Lead has been commonly used in households for millennia in all kinds of applications, such as in pots, pans, pipes and paints. However, since the $19^{\text {th }}$ century the toxic effects of non-metallic lead have become apparent. In particular, water soluble lead salts are potentially very harmful, as they can be easily taken up by living organisms, where a small daily dose of $1 \mathrm{mg}$ results in chronic lead poisoning symptoms in humans, such as birth defects. ${ }^{31-33}$ In the case of perovskite solar cells, lead is present in the $2^{+}$oxidation state, which makes it soluble in water and thus a hazard to human health if the cells are employed in large scale applications.

The largest solar parks in Europe consist of active areas of over 200 hectares. Assuming that stateof-the-art perovskite solar cells would replace the widely employed silicon-based solar panels, the total lead content of such a solar park would be over $800 \mathrm{~kg}$ (see Supporting Information). Without a proper way of handling these large amounts, general support for such a park would be unlikely due to the well-known dangers of lead. 
An accurate cost estimation of the recycling procedure at this point is challenging since many assumptions have to be made. Both the cost of the recycling process and the cost of perovskite based solar panels, produced on an industrial scale, are difficult to evaluate. However, the cost of transportation and dismantling are unavoidable since the panels have to be collected after their operation lifetime in accordance with international electronic waste disposal laws. The additional costs for the recycling are expected to be relatively low since the process presented here is entirely based on low temperature solution steps. In addition to being economically attractive once perovskite solar cells are produced on a large scale, the recycling of the FTO substrate is already of interest for research facilities and startup companies. As demonstrated, the expensive FTO substrates can be recycled in a simple and low-cost process, which reduces the overall material cost and also saves production time since the recycled substrates are already patterned and cut to the appropriate size.

\section{Conclusions}

In conclusion, we have demonstrated an environmentally responsible and cost-efficient recycling process for solar cells based on $\mathrm{MAPbI}_{3}$. Our results show that perovskite solar cells can be stripped down in a layer-by-layer approach, and that the collected materials can be reused without significant losses to device performance. In particular, we show that the toxic $\mathrm{PbI}_{2}$ can be recycled and, after recrystallization, can be employed to prepare devices exhibiting power conversion efficiencies up to $13.5 \%$. With this approach, the risk of lead contaminating the environment can be decreased, while still retaining $\mathrm{PbI}_{2}$ as the starting material for the production of highly efficient solar cells. In addition, we were able to recycle the expensive FTO/glass substrates several times without significant loss of device performance on solar cells exhibiting PCEs exceeding $15 \%$. This

work demonstrates a process to address the environmental and health issues of lead based- 
perovskite solar cells and combines this with a cost-reducing recycling process, bringing perovskite solar cells one step closer to their introduction into commercial systems. 


\section{Acknowledgements}

The authors acknowledge funding from the German Federal Ministry of Education and Research (BMBF) under the agreement number 01162525/1, the Bavarian Ministry of the Environment and Consumer Protection, the Bavarian Network "Solar Technologies Go Hybrid", and the DFG Excellence Cluster Nanosystems Initiative Munich (NIM). P. D. acknowledges support from the European Union through the award of a Marie Curie Intra-European Fellowship. 


\section{References}

1. United Nations Framework Convention on Climate Change (UNFCCC), Adoption of the Paris Agreement, FCCC/CP/2015/L.9/Rev.1. Paris, 2015.

2. Lee, M. M.; Teuscher, J.; Miyasaka, T.; Murakami, T. N.; Snaith, H. J., Efficient Hybrid Solar Cells Based on Meso-Superstructured Organometal Halide Perovskites. Science 2012, 338 (6107), 643-647.

3. Burschka, J.; Pellet, N.; Moon, S.-J.; Humphry-Baker, R.; Gao, P.; Nazeeruddin, M. K.; Grätzel, M., Sequential deposition as a route to high-performance perovskite-sensitized solar cells. Nature $\mathbf{2 0 1 3}, 499$ (7458), 316-319.

4. Xiao, M.; Huang, F.; Huang, W.; Dkhissi, Y.; Zhu, Y.; Etheridge, J.; Gray-Weale, A.; Bach, U.; Cheng, Y.-B.; Spiccia, L., A Fast Deposition-Crystallization Procedure for Highly Efficient Lead lodide Perovskite Thin-Film Solar Cells. Angew. Chem. Int. Ed. 2014, 126 (37), 10056-10061.

5. Xiao, Z.; Bi, C.; Shao, Y.; Dong, Q.; Wang, Q.; Yuan, Y.; Wang, C.; Gao, Y.; Huang, J., Efficient, High Yield Perovskite Photovoltaic Devices Grown by Interdiffusion of Solution-Processed Precursor Stacking Layers. Energy Environ. Sci. 2014, 7, 2619-2623.

6. $\quad$ Nie, W.; Gupta, G.; Crone, B. K.; Liu, F.; Smith, D. L.; Ruden, P. P.; Kuo, C.-Y.; Tsai, H.; Wang, H.-L.; Li, H.; Tretiak, S.; Mohite, A. D., Interface Design Principles for High-Performance Organic Semiconductor Devices. Adv. Sci. 2015, 2 (6), 1-7.

7. Eperon, G. E.; Burlakov, V. M.; Docampo, P.; Goriely, A.; Snaith, H. J., Morphological Control for High Performance, Solution-Processed Planar Heterojunction Perovskite Solar Cells. Adv. Funct. Mater. 2013, 151.

8. Xie, F. X.; Zhang, D.; Su, H.; Ren, X.; Wong, K. S.; Grätzel, M.; Choy, W. C. H., Vacuum-Assisted Thermal Annealing of CH3NH3Pbl3 for Highly Stable and Efficient Perovskite Solar Cells. ACS Nano 2015, 9, 639-646.

9. Docampo, P.; Ball, J. M.; Darwich, M.; Eperon, G. E.; Snaith, H. J., Efficient organometal trihalide perovskite planar-heterojunction solar cells on flexible polymer substrates. Nat. Commun. 2013, 4, 2761.

10. Zhou, H.; Chen, Q.; Li, G.; Luo, S.; Song, T.-b.; Duan, H.-S.; Hong, Z.; You, J.; Liu, Y.; Yang, Y., Interface engineering of highly efficient perovskite solar cells. Science 2014, 345 (6196), 542-546.

11. Green, M. A.; Emery, K.; Hishikawa, Y.; Warta, W.; Dunlop, E. D., Solar cell efficiency tables (Version 45). Prog. Photovoltaics 2015, 23 (1), 1-9.

12. Patrick, L., Lead toxicity, a review of the literature. Part 1: Exposure, evaluation, and treatment. Altern Med Rev 2006, 11 (1), 2-22.

13. Benmessaoud, I. R.; Mahul-Mellier, A.-L.; Horvath, E.; Maco, B.; Spina, M.; Lashuel, H.; Forro, L., Health hazard of the Methylammonium Lead lodide based Perovskites: cytotoxicity studies. Toxicol Res 2015, 1-13.

14. Needleman, H., Lead poisoning. Annu Rev Med 2004, 55, 209-22.

15. Toscano, C. D.; Guilarte, T. R., Lead neurotoxicity: From exposure to molecular effects. Brain. Res. Rev. 2005, 49 (3), 529-554.

16. Pourrut, B.; Shahid, M.; Dumat, C.; Winterton, P.; Pinelli, E., Lead Uptake, Toxicity, and Detoxification in Plants. Reviews of Environmental Contamination and Toxicology 2011, 213, 113-136.

17. Hao, F.; Stoumpos, C. C.; Cao, D. H.; Chang, R. P. H.; Kanatzidis, M. G., Lead-free solid-state organicinorganic halide perovskite solar cells. Nat Photon 2014, 8 (6), 489-494.

18. European Parliament, Directive 2002/96/EC of the European Parliament and of the Council of 27 January 2003 on waste electrical and electronic equipment (WEEE). Off. J. Eur. Union: L37, 2003; pp 2439.

19. European Parliament, Directive 2012/19/EU of the European Parliament and of the Council of 4 July 2012 on waste electrical and electronic equipment (WEEE). Off. J. Eur. Union L197, 2012; pp 38-71. 
20. Candelise, C.; Winskel, M.; Gross, R., Implications for CdTe and CIGS technologies production costs of indium and tellurium scarcity. Prog. Photovoltaics 2012, 20 (6), 816-831.

21. Kalowekamo, J.; Baker, E., Estimating the manufacturing cost of purely organic solar cells. Sol. Energy 2009, 83 (8), 1224-1231.

22. Sun, K.; Li, P.; Xia, Y.; Chang, J.; Ouyang, J., Transparent conductive oxide-free perovskite solar cells with PEDOT:PSS as transparent electrode. ACS App. Mater. Interfaces 2015, 7 (28), 15314-15320.

23. Sung, H.; Ahn, N.; Jang, M. S.; Lee, J.-K.; Yoon, H.; Park, N.-G.; Choi, M., Transparent Conductive Oxide-Free Graphene-Based Perovskite Solar Cells with over 17\% Efficiency. Adv. Energy Mater. 2015, 16.

24. Petrus, M. L.; Bein, T.; Dingemans, T. J.; Docampo, P., A low cost azomethine-based hole transporting material for perovskite photovoltaics. J. Mater. Chem. A 2015, 3, 12159-12162.

25. Liu, J.; Pathak, S.; Stergiopoulos, T.; Leijtens, T.; Wojciechowski, K.; Schumann, S.; Kausch-Busies, N.; Snaith, H. J., Employing PEDOT as the p-Type Charge Collection Layer in Regular Organic-Inorganic Perovskite Solar Cells. J. Phys. Chem. Lett. 2015, 1666-1673.

26. Saliba, M.; Orlandi, S.; Matsui, T.; Aghazada, S.; Cavazzini, M.; Correa-Baena, J.-P.; Gao, P.; Scopelliti, R.; Mosconi, E.; Dahmen, K.-H.; De Angelis, F.; Abate, A.; Hagfeldt, A.; Pozzi, G.; Grätzel, M.; Nazeeruddin, M. K., A molecularly engineered hole-transporting material for efficient perovskite solar cells. Nature Energy 2016, 15017.

27. Lee, M.; Ko, Y.; Min, B. K.; Jun, Y., Silver Nanowire Top Electrodes in Flexible Perovskite Solar Cells using Titanium Metal as Substrate. ChemSusChem 2015, 31-35.

28. Kim, A.; Lee, H.; Kwon, H.-C.; Jung, H. S.; Park, N.-G.; Jeong, S.; Moon, J., Fully Solution-Processed Transparent Electrodes Based on Silver Nanowire Composites for Perovskite Solar Cells. Nanoscale 2015.

29. Ponpon, J. P.; Amann, M., Properties of solution grown Pbl2 layers embedded in PVA. Cryst. Res. Technol. 2007, 42 (3), 253-259.

30. Othmer, K., Encyclopedia of Chemical Technology. 5 ed.; 2007; Vol. 1-26, p 1084.

31. Goyer, R. A.; Clarkson, T. W., Toxic effects of metals. Casarett \& Doull's Toxicology. The Basic Science of Poisons, Fifth Edition, Klaassen, CD [Ed]. McGraw-Hill Health Professions Division, ISBN 1996, 71054766.

32. Demayo, A.; Taylor, M. C.; Taylor, K. W.; Hodson, P. V.; Hammond, P. B., Toxic effects of lead and lead compounds on human health, aquatic life, wildlife plants, and livestock. Crit. Rev. Env. Contr. 1982, 12 (4), 257-305.

33. Goyer, R. A., Lead toxicity: from overt to subclinical to subtle health effects. Environ. Health Perspect. 1990, 86, 177-181. 